\title{
Employee External Communication Behavior during the COVID-19 Pandemic Crisis: Case-study of a State-Owned \\ Company
}

\author{
Adam Priyo Perdana* \\ Management Department, BINUS Business School Master Program, Bina Nusantara \\ University, Jakarta, Indonesia
}

\section{Lusi Latifunnur}

Management Department, BINUS Business School Master Program, Bina Nusantara University, Jakarta, Indonesia

\section{Evelyn Hendriana}

Management Department, BINUS Business School Master Program, Bina Nusantara University, Jakarta, Indonesia

*Corresponding author: adam.perdana@binus.ac.id

\section{Abstract}

A crisis can trigger employees to engage in external communication behavior. However, the inconsistency of the findings of studies on megaphoning behavior suggests the relationship depends on the type of crisis. With the COVID-19 pandemic crisis, this study aims to examine the influence of employee-organization relations and symmetrical internal communication on employee external communication behavior. Data were collected from 400 employees of a state-owned company in Indonesia and analyzed using PLS-SEM. The result shows that good relations between employees and organization can encourage employees to stand up for the company, reduce employee's intention to share negative communications, encourage employees to recognize crisis as a serious problem, can make employees feel more involved and less constrained in resolving the problems. Employees who feel that they could recognize the crisis tend to spread positive information and restraint from sharing negative information. Meanwhile, those who feel that they were involved in the crisis and less constrained in solving the problem do not influence their interest in spreading positive or negative information. The study finds that symmetrical communication between employees and their companies may encourage employees to spread positive information, but it did not affect their interest in disseminating negative information.

Keywords: Employee-organization relationship, Situational theory of problem solving, Positive megaphoning, Negative megaphoning, Symmetrical internal communication. 


\section{Introduction}

The current COVID-19 pandemic caused a global economic shock due to the government's transmission control policies that restricted the movement of people and goods (World Bank, 2020). This economic downturn is experienced by all countries, including countries with a significant and stable growth in the last five years, such as China, India, and Indonesia. In Indonesia, the four sectors affected the most by the the COVID-19 pandemic include households, SMEs, corporations, and the financial sector. The crisis in the corporate sector occurred due to a decline in the company's business performance because of the pressure in the supply chain, trade, and changes in consumer behavior.

Organizational crises, as unpredictable events, create ambiguity, uncertainty, and challenges to regain control in an organization (Coombs, 2015). In the internal part of an organization, a crisis creates ambiguity and uncertainty for the internal public, namely employees (Ulmer et al., 2019). Several researchers have emphasized that employees are a distinct part of the public who need to get individual attention through internal communication (Kang \& Sung, 2017; Park et al., 2014). When a crisis occurs, employees can have positive or negative communicative behaviors towards their organization. Both behaviors can reduce or even increase threats (Kim \& Rhee, 2011).. According to Center and Jackson (2003), employee communication behavior with the external public is crucial because the public considers it to be more neutral than formal public relations messages. Given that employee interactions with the external public can affect public relations output as well as the company reputation and the quality of public-organizational relations, it is important to understand employee communication when the company is facing a crisis because employees communicate more intensely during the crisis (Johansen et al., 2012).

Several studies show employee communication behavior is influenced by the employee-organization relationships (hereafter, EOR). Mazzei et al. (2012), Kim and Rhee (2011), Lee (2017), and Frandsen and Johansen (2011) reported that a good EOR will lead employees to support their company. However, Kang and Sung (2017) and Lee (2019) found that the relationship was insignificant. A good EOR also affects employees' perceptions, attitudes, and positive behavior toward the crisis (Hung, 2005; Ki \& Hon 2007). Lee (2020) found that pre-crisis EOR had a significant effect on three dimensions of crisis perception, namely problem recognition, constraint recognition, and involvement recognition. Kang and Sung (2017) reported that a good EOR increased problem recognition and involvement recognition, but it did not affect constraint recognition.

Specific crisis perceptions have also been found to influence communication behavior. Kim and Grunig (2011) showed that people who recognized and involved in the problem, while less constrained in solving the problem, tended to share and forward the information more intensely. However, it has not been specifically explained to what extent these variables influence negative communication behavior. Ni et al. (2019) explained that information sharing is significantly influenced by the introduction of involvement and recognition of constraints, but not significantly influenced by problem recognition. Similarly, Lee (2019) found that only two dimensions of employee crisis perception variables significantly affect negative megaphoning behavior, i.e., involvement recognition and constraint recognition. In a later study, Lee (2020) 
explained that only crisis perception and constraint recognition that have a significant effect on employee voicing behavior in crisis conditions.

Symmetrical communication is an excellent communication practice (Kim \& Rhee, 2011; Men \& Bowen, 2017) that is needed in crisis management. Kang and Sung (2017), Kim (2018), and Kim and Rhee (2011) reported a positive relationship between symmetrical communication and employee communication behavior, but they did not look specifically at the effect of symmetric communicative behavior on negative employee communication behavior externally. As such, Lee (2020) suggests exploring how communication strategies can affect employees' megaphoning behavior during a crisis.

This study lies on situational theory of problem solving (STOPS) and advances the current research by examining the interrelationships among variables in STOPS, EOR, and symmetrical communication practice. Among a few empirical studies on the factors that influence megaphoning behavior, there is sufficient evidence that this topic has not been resolved. There are still inconsistent, contradictory, and uncertain arguments about the megaphoning communication behavior of employees in the organization during a crisis. It indicates a research gap to verify the theory regarding variables that are thought to influence employee's megaphoning behavior during an organizational crisis.

From a managerial perspective, this study highlights key variables of employee's megaphoning behavior during the crisis. Referring to Lee $(2019,2020)$, employee's communication behavior can differ depending on the crisis that occurs. Most types of crisis in previous studies were caused by internal factors. The situation of the COVID19 pandemic is caused by external factor, relatively new and still ongoing with a high level of uncertainty and has a multidimensional impact. As such, our findings may give insights to the management on the factors that they have to focus on to maximize the positive megaphoning behavior and minimize the negative megaphoning behavior. This study aims to analyze the mediating effect of employee-specific crisis perception in the correlation between EOR and employee megaphoning behavior and the direct effect of symmetrical internal communication on employee megaphoning behavior, while controlling for other potential sources of megaphoning behavior such as age, gender, tenure, and managerial position.

\section{Literature Review}

\section{Theoretical Framework}

This study uses situational theory of problem solving (STOPS) as the underpinning theory. This theory refines the situational theory of public (theory of public) which explains that information consumption becomes systematic when people feel that information appropriate to their life problems (Grunig, 1997). The situational theory of public adopted a narrow conceptualization as it uses only information acquisition (information seeking or attending) to describe an active communication behavior. The theory is also not able to explain and classify the behaviors of the public. In its original formulation, the theory of public only considered perceptual variables as causal antecedents to communication behavior. 
Therefore, Kim and Grunig (2011) introduces the situational theory of problem solving (STOPS) as a framework to better understand the behavioral motivation. STOPS assumes that most human behavior is motivated by problem-solving. This theory explains that communicative behavior is the result of the problem-solving process. When a problem or a crisis arises in an organization, employees will go through a cognitive process before they choose to do something or remain silent in response to the crisis. This theory states explicitly that employee communication behavior is influenced by three variables: problem recognition, involvement recognition, and constraint recognition as presented in Figure 1. Researchers have also noted its theoretical significance and application to organizational and internal communication (Park et al., 2014; Men \& Bowen, 2017) that have been tested in various problems or crisis (e.g., Kang \& Sung, 2017; Kim \& Grunig, 2011; Lee, 2019, 2020; Ni et al., 2019). The application of STOPS in this study is shown through the relationship between three certain crisis perceptions and megaphoning behavior. Furthermore, this study extends STOPS by attaching EOR as antecedents of three specific crisis perceptions in STOPS model and symmetrical communication as determinant of megaphoning behavior.

Figure 1: Theoretical Framework

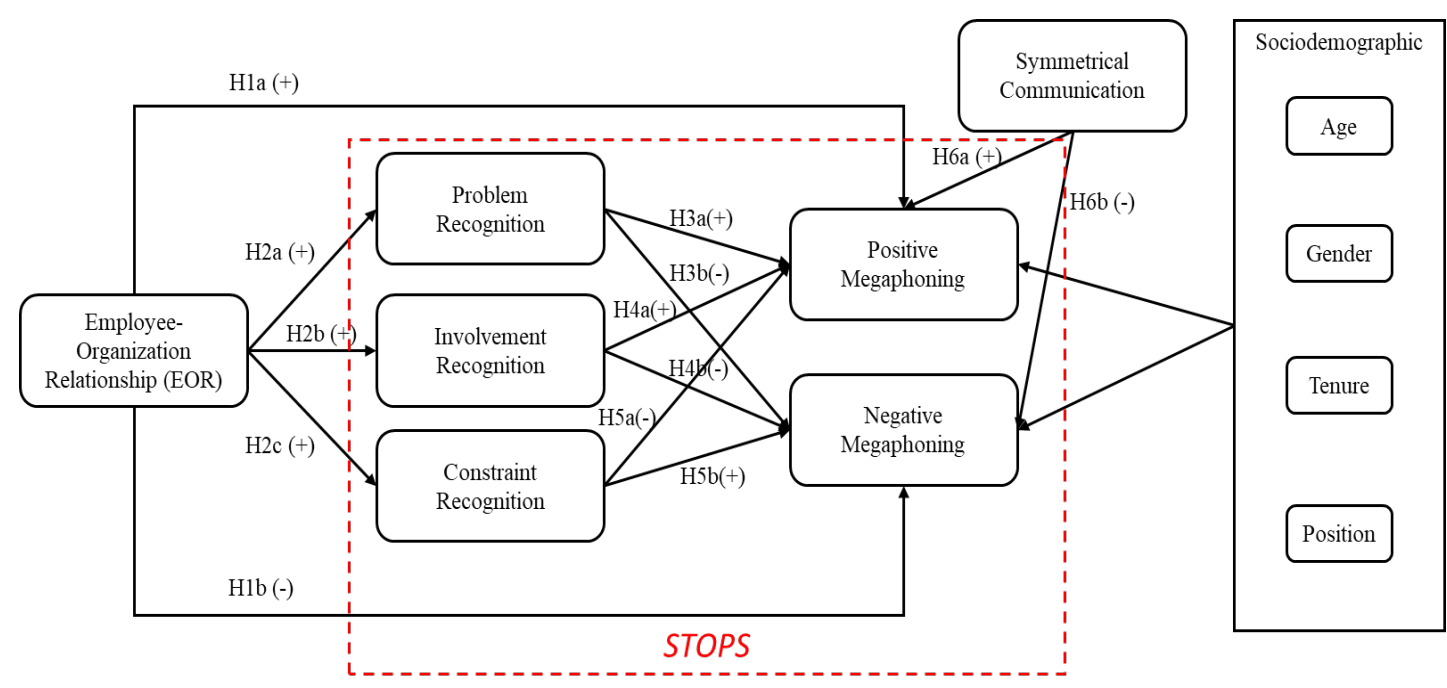

\section{Employee Communication Behavior during a Crisis}

Strandberg and Vigsø (2016) explained that internal crisis communication is a situation where employees interpret and understand managing crisis communication in organizations. Several scholars believed that organization need to give individual attention through internal communication (Kang \& Sung, 2017; Park et al., 2014). As a part of valuable characteristics, employees are involved in boundary-spanning activities, where interactions can be internal or external to the company to collect, select and convey information from the environment to decision-makers or other internal members of the organization (Grunig \& Repper, 1992).

Kim and Rhee (2011) and Kang and Sung (2017) explained that one of the concepts of boundary-spanning activities is employee communication behavior (ECB), as this concept emphasizes the positive and negative effects of searching and delivering 
information behavior. Therefore, understanding employee's communication behavior is essential to achieve communication effectiveness in crisis conditions (Mazzei et al., 2012).

When employees communicate externally, it can affect the reputation and performance of the organization. This behavior is critical for organizations during crisis periods because employees communicate more intensely during a crisis (Johansen et al., 2012; Kim \& Rhee, 2011). When employees can identify the problem, they intensely forward supporting information about the company and stand up for the company through positive megaphoning (Mazzei et al., 2012). In contrast, they can also have negative megaphoning behavior, by criticizing or blaming the company (Kim \& Rhee, 2011; Kim, 2018; Lee, 2017). Focusing on the behavior of disseminating organizational information externally during periods of an organizational crisis, this study seeks to understand what factors influence employees to engage in megaphoning communication behavior.

\section{Employee-Organization Relationship (EOR)}

Kim and Rhee (2011) and Men (2011) revealed that an organization's relationship with its employees contributes to the organizational performance, the achievement of organizational goals, and the formation of the organization's reputation and image in a turbulent environment. Hon and Grunig (1999) and Kim and Rhee (2011) defined EOR as the level at which an organization and its employees trust each other (trust), agree on who has the legitimate power to influence (control mutuality), experience satisfaction with each other (satisfaction), and commit to one another (commitment).

EOR has many positive outcomes for the organization and employees. It affects the performance, job satisfaction, affective commitment, turnover intention, perception of work options, goal achievement, and organizational reputation protection (Men, 2012; Morrison \& Robinson, 1997). The importance of the quality of the relationship between the organization and employees to manage organizational crises effectively has also been emphasized in several previous studies (Frandsen \& Johansen, 2011; Lee, 2017; Mazzei \& Ravazzani, 2011). A positive EOR might strengthen positive employee megaphoning behavior and reduce negative megaphoning behavior (Kim \& Rhee, 2011; Lee 2017, Mazzei et al., 2012). Previous studies were conducted in several types of crises, such as a managerial crisis, recall, consumer claims, information leakage (Kim \& Rhee, 2011), work accidents (Mazzei et al., 2012), customer complaints, employee problems, violence at work, lawsuits, strikes, and mismanagement (Lee, 2017).

Apart from these scholars, Kang and Sung (2017) found that good EOR only increased positive megaphoning, but not negative megaphoning. Similarly, Lee (2019) showed that EOR before the crisis did not reduce their intention to spread negative information outside the company. This suggests that an employee's perceptions of a crisis and communicative behavior can vary based on the organization's responsibility, organizational communication strategies or apologies, and sources of crisis causes (Coombs, 2007; Coombs \& Holladay, 2006; Lee, 2019). Kim (2018) also explained that each crisis has different crisis characteristics in terms of the level of uncertainty and time pressure, which result in different employee communication behavior (Frandsen \& Johansen, 2011). 
The findings from several previous studies have shown the effect of EOR on employee's external communication behavior during times of crisis. The good quality of EOR can increase employee confidence about crisis management in the organization that affects their attitudes and ways of expressing their opinions to the external public. Employees who have a good quality relationship with their organization are predicted to have good external communication behavior and high levels of trust, understanding, satisfaction, and commitment to the organization. Based on these arguments, this study proposes the following hypothesis:

H1 The employee-organization relationship has a positive effect on positive megaphoning (H1a) and a negative effect on negative megaphoning (H1b)

\section{Specific Crisis Perceptions}

Communicative behavior is an outcome of a problem-solving process, in which the situational theory of problem solving (STOPS) can be used to understand employee's motivation to do such behavior (Kim \& Grunig, 2011). STOPS can predict various communicative behaviors by explaining the underlying reasons of people actively communicating. This theory states explicitly that employee communication behavior is determined by three variables: problem recognition, involvement recognition, and constraint recognition. Problem recognition refers to a person's perception that something is problematic, and there is no immediate solution. Involvement recognition describes the perceived relationship between individuals and problematic situations. Constraint recognition shows the perception of obstacles that limit a person's ability to do something about a situation.

\section{The Relationship of EOR and Specific Crisis Perceptions}

Not only directly affecting the employee communication behavior, EOR also influences employee perceptions of the crisis. This condition occurs because EOR affects employee cognitive perceptions of certain situations, namely how employees recognize a problem, involvement in a problem, and perceptions of obstacles to solve a problem (Kim \& Grunig, 2011). Employee perceptions about a problem ultimately affect employee motivation to be actively involved in positive and negative communication behavior towards a crisis. When employees who have a positive relationship with their organization find that their company is experiencing a problem or a crisis, they are cognitively aware that the issue is strongly related to their lives or work and that they can make a difference in the issue (Lee, 2020).

Several studies about the influence of internal-organizational public relations show that internal public-organizational ties lead to positive perceptions, attitudes, and behavior of employees (Hung, 2005; Ki \& Hon, 2007). To strengthen this research, Lee (2020) found show that pre-crisis EOR has a significant effect on the three dimensions of crisis perception: problem recognition, constraint recognition, and involvement recognition. However, Kang and Sung (2017) reported that good EOR only increased problem recognition and involvement recognition but had no significant effect in reducing constraint recognition. Several previous research results have shown the effect of EOR on employee's specific crisis perceptions during crisis times. Employees who have a good quality relationship with their organization are predicted to have the ability to recognize problems better, feel more involved in these problems and feel less 
constrained in solving these problems along with their better cognitive processes regarding the problems faced by the organization. Based on these arguments, this study will test the following hypotheses:

H2 Employee-organization relationships have a positive effect on problem recognition $(\mathrm{H} 2 \mathrm{a})$, involvement recognition $(\mathrm{H} 2 \mathrm{~b})$, and constraint recognition $(\mathrm{H} 2 \mathrm{c})$

\section{The Relationship of Specific Crisis Perceptions and Megaphoning Behavior}

Previous research has indicated that employee perceptions of organizational problems - whether they feel they are able to recognize the problem, be concerned about the problem, and feel confident in solving the problem - play an essential role in encouraging them to communicate intensely. Kim and Rhee (2011) illuminated that when employees perceive their organizational problems or crises as theirs, they are likely to be involved in a communicative behavior, such as conveying information to defend or criticize their company. This suggests that employee situational perceptions may direct their communicative actions, especially towards a recent problem. There might be some obstacles that restrict employees to solve the problem, which will affect their communicative behavior. When employees are perceived to be less constrained in solving the problem and think that they can alter the situation, they will be more likely to communicate (Kim \& Grunig, 2011).

Research conducted by Kim and Grunig (2011) about the relationship of specific crisis perceptions and megaphoning has not specifically influenced negative communication behavior. Besides that, a study by Lee (2019) indicates an insignificant relationship between the effect of problem recognition and positive megaphoning and negative megaphoning as well as between involvement recognition and positive megaphoning. Meanwhile, research by $\mathrm{Ni}$ et al. (2019) explained that information sharing is significantly influenced by involvement recognition and constraint recognition, but not considerably influenced by problem recognition. In a more recent study, Lee (2020) found that the dimensions of problem recognition and constraint recognition had a significant impact on employees voicing behavior in crisis conditions, while involvement recognition had no significant effect.

The findings of several previous studies have shown the effect of employee's specific crisis perceptions on their external communication behavior during times of crisis. Employees who can recognize problems better, have high awareness, and feel more confident in solving problems are predicted to have positive external communication behavior along with the better their situational evaluation of the problems faced by the company so that they tend to perceive organizational problems as their problems. Otherwise, employees who cannot recognize problems, do not care, and feel that there are many obstacles in solving problems are predicted to have negative external communication behavior because they think organizational problems are not related to them.

Based on these arguments, this study will test the following hypotheses:

H3 Problem recognition has a positive effect on positive megaphoning (H3a) and a negative effect on negative megaphoning (H3b) 
H4 Involvement recognition has a positive effect on positive megaphoning (H4a) and a negative effect on negative megaphoning ( $\mathrm{H} 4 \mathrm{~b})$

H5 Constraint recognition has a negative effect on positive megaphoning (H5a) and a positive effect on negative megaphoning $(\mathrm{H} 5 \mathrm{~b})$

\section{Symmetrical Internal Crisis Communication}

Symmetrical internal communication is considered as a superior communication practice as it adopts a two-way balanced public relations communication model (Grunig, 1992; Kim \& Rhee, 2011; Men \& Bowen, 2017). This concept is an employeecentered communication style that highlights openness, negotiation, trust, and credibility (Grunig, 1992, p. 558).

Kang and Sung (2017), Kim (2018), as well as Kim and Rhee (2011) found that symmetrical communication can strengthen employee communication behavior. In line with these findings, Lee's research (2020) shows that balanced communication positively affects employees seeking and voicing communication behavior during a crisis. However, a study conducted by Men (2014) found that symmetrical communication was not significant in influencing employee communication behavior, particularly employee advocacy.

In addition, previous studies have not explicitly looked at the effect of symmetrical communication on negative megaphoning. Given the importance of employee communication behavior outside the organization, further research is needed to explore how communication strategies can influence employee external communication behavior during a crisis. Considering that the crisis that occurred in an organization as a result of the COVID-19 pandemic originated from external companies and there has never been an organization that was ready to experience this crisis, it is still necessary to know the effect of implementing symmetrical communication on employee megaphoning. Tthis study predicts that the application of symmetrical communication will increase positive external communication behavior along with the better level of trust and understanding in the organization. Therefore, the following hypothesis is developed:

H6 Symmetrical communication has a positive effect on positive megaphoning behavior (H6a) and a negative impact on negative megaphoning behavior (H6b).

\section{Methodology}

\section{Research Context}

According to the Ministry of Finance of the Republic of Indonesia (2020), Indonesia officially experienced a recession due to the COVID-19 pandemic. This causes companies revenue to fall sharply, and they are threatened with bankruptcy. This condition can also undoubtedly affect the capital market performance, where almost all companies listed on the stock exchange experienced a decline in performance, followed by a decrease in the value of their stock market capitalization. The decline in economic activities, as experienced in almost all sectors, automatically leads companies to 
increase their efficiency in order to minimize loss. As a result, many companies have to reduce or stop their operations and lay off their employees.

\section{Research Method}

The population for this study was employees of a state-owned company presence in almost every region of Indonesia. Currently, the company is experiencing a health crisis at work and financial problems due to a sharp decline in sales caused by the COVID19 pandemic. The survey was conducted with 400 respondents from various levels of positions. Samples were selected using proportionate - stratified random sampling based on the level of position: top manager, middle manager, lower manager, top supervisor, lower supervisor, and staff/nonstructural. The final sample consisted of $1.25 \%$ of top manager $(n=5), 2 \%$ of middle manager $(n=8), 9.25 \%$ of lower manager $(n=37), 16.25 \%$ of top supervisor $(n=65), 28.75 \%$ of lower supervisor $(n=115)$, and $42.5 \%$ of $\operatorname{staff}(n=170)$. This percentage is based on the number of employees who held these positions in 2020 as per data that was obtained from the Human Capital Division. Data was collected through a survey from July to August 2020 by distributing questionnaires electronically using the Google Forms application. Questionnaires were distributed to 1000 employee of which 680 were returned. After filtering for unengaged and incomplete responses, this study used 400 responses for data analysis. The demographic profiles of the respondents are shown in Table 1.

Table 1: Demographic Profiles of the Respondents

\begin{tabular}{lcc}
\hline \multicolumn{1}{c}{ Demographic Profile } & Frequency & Percentage (\%) \\
\hline Job Position: & 5 & \\
Upper-level Manager & 8 & $1.25 \%$ \\
Middle-level Manager & 37 & $2.00 \%$ \\
Lower-level Manager & 65 & $9.25 \%$ \\
Upper-level Supervisor & 115 & $16.25 \%$ \\
Lower-level Supervisor & 170 & $28.75 \%$ \\
Staff/Non-Structural & & $42.50 \%$ \\
Age: & 31 & \\
<26 & 131 & $7.75 \%$ \\
26-30 & 75 & $32.75 \%$ \\
31-35 & 75 & $18.75 \%$ \\
$36-40$ & 17 & $18.75 \%$ \\
41-45 & 42 & $4.25 \%$ \\
46-50 & 29 & $10.5 \%$ \\
$>50$ & & $7.25 \%$ \\
Gender: & 350 & \\
Male & 50 & $87.5 \%$ \\
Female & & $12.5 \%$ \\
Working Period: & 85 & \\
1-5 years & 120 & $21 \%$ \\
6-10 years & 105 & $30 \%$ \\
11-15 years & 90 & $26 \%$ \\
>15 years & & $23 \%$ \\
Educational background: & 113 & \\
High School & 261 & $28.5 \%$ \\
Bachelor's Degree & 25 & $65.25 \%$ \\
Master's Degree & 1 & $0.25 \%$ \\
Doctoral Degree & &
\end{tabular}


All the measurement items were adopted from literature, and some items were excluded in the main study based on the validity and reliability tests of the pilot test. The EOR variable is a multidimensional variable consisting of trust, control mutuality, commitment, and satisfaction. Trust is measured by five instruments, control mutuality variable by four instruments, commitment by three instruments, and satisfaction by four instruments. All instruments were adopted from Hon and Grunig (1999). Problem recognition was measured by six instruments, constrain recognition by five instruments, and involvement recognition by five instruments, as adopted from Kim and Grunig (2011). Simultaneously, positive megaphoning was measured by six instruments and negative megaphoning by four instruments from Kang and Sung (2017) and Lee (2017). Seven instruments that measured the symmetrical communication variable were adopted from Kim and Rhee (2011) and Kim (2018). All items were measured using a 5-point Likert scale.

The selection of SEM technique should be based on several considerations, such as research objective, measurement and structural model, data characteristics, and model evaluation (Hair et al., 2011, 2014; Ramayah et al., 2018). This study used PLS-SEM as it is believed as a powerful tool to predict relationships between variables, particularly for complex model and has identification issues (Hair et al., 2011). Even though this technique has been debated in the past (Gefen, Straub \& Boudreau, 2000; Hair et al., 2014), its shortcomings have been solved through the assessment of measurement model characteristics (Hair et al., 2011), the use of large sample size (Hair et al., 2011), and the calculation of HTMT ratio for discriminant validity evaluation (Henseler et al., 2015).

This research aims to predict and identify key constructs that form employee external communication behavior by integrating EOR and symmetrical communication into the STOPS model. As such, PLS-SEM seems to be more appropriate tool for data analysis. Furthermore, the research framework was relatively complex, and one of the variables was measured with three items only. The data also did not meet the multivariate normality assumption (Mardia's skewness $b=1177.971$, $p$-value $=0.000$; kurtosis $b=$ 4754.789, $\mathrm{p}$-value $=0.000$ ). The PLS-SEM software used in this study is SmartPLS 3.0 .

\section{Results}

As shown in Table 2, all the retained items in the main study satisfied the convergent validity with a factor loading and AVE above 0.5 and composite reliability above 0.7 . Table 3 shows that all the HTMT ratios are below 0.85 , which indicates the discriminant validity has been fulfilled. 
Table 2: Reliability and Validity Test Results

\begin{tabular}{|c|c|c|c|c|c|}
\hline Construct & Indicator & Loading & $\begin{array}{l}\text { Composite } \\
\text { Reliability }\end{array}$ & AVE & $\begin{array}{c}\text { Cronbach's } \\
\text { Alpha }\end{array}$ \\
\hline \multirow[t]{5}{*}{ Trust } & TR1 & 0.802 & 0.907 & 0.662 & 0.873 \\
\hline & TR2 & 0.808 & & & \\
\hline & TR3 & 0.787 & & & \\
\hline & TR4 & 0.844 & & & \\
\hline & TR6 & 0.828 & & & \\
\hline \multirow[t]{4}{*}{ Control Mutuality } & CMU3 & 0.849 & 0.910 & 0.716 & 0.868 \\
\hline & CMU4 & 0.838 & & & \\
\hline & CMU5 & 0.865 & & & \\
\hline & CMU6 & 0.832 & & & \\
\hline \multirow[t]{3}{*}{ Commitment } & CMT1 & 0.897 & 0.917 & 0.786 & 0.864 \\
\hline & CMT2 & 0.908 & & & \\
\hline & CMT3 & 0.854 & & & \\
\hline \multirow[t]{4}{*}{ Satisfaction } & ST1 & 0.889 & 0.952 & 0.833 & 0.933 \\
\hline & ST2 & 0.926 & & & \\
\hline & ST3 & 0.915 & & & \\
\hline & ST4 & 0.920 & & & \\
\hline \multirow[t]{6}{*}{ Problem Recognition } & PR1 & 0.818 & 0.940 & 0.723 & 0.924 \\
\hline & PR2 & 0.862 & & & \\
\hline & PR4 & 0.869 & & & \\
\hline & PR5 & 0.812 & & & \\
\hline & PR6 & 0.856 & & & \\
\hline & PR7 & 0.883 & & & \\
\hline Constraint & CR1 & 0.817 & 0.939 & 0.754 & 0.918 \\
\hline \multirow[t]{4}{*}{ Recognition } & CR3 & 0.879 & & & \\
\hline & CR4 & 0.900 & & & \\
\hline & CR5 & 0.876 & & & \\
\hline & CR7 & 0.868 & & & \\
\hline Involvement & IR1 & 0.914 & 0.953 & 0.804 & 0.938 \\
\hline \multirow[t]{4}{*}{ Recognition } & IR2 & 0.930 & & & \\
\hline & IR3 & 0.930 & & & \\
\hline & IR4 & 0.929 & & & \\
\hline & IR5 & 0.771 & & & \\
\hline Positive & PM1 & 0.801 & 0.915 & 0.643 & 0.888 \\
\hline \multirow[t]{5}{*}{ Megaphoning } & PM2 & 0.854 & & & \\
\hline & PM3 & 0.779 & & & \\
\hline & PM4 & 0.697 & & & \\
\hline & PM5 & 0.839 & & & \\
\hline & PM6 & 0.833 & & & \\
\hline Negative & NM1 & 0.912 & 0.943 & 0.807 & 0.920 \\
\hline \multirow[t]{3}{*}{ Megaphoning } & NM2 & 0.899 & & & \\
\hline & NM5 & 0.927 & & & \\
\hline & NM6 & 0.853 & & & \\
\hline Symmetrical & TWC1 & 0.784 & 0.927 & 0.645 & 0.907 \\
\hline \multirow[t]{6}{*}{ Communication } & TWC2 & 0.847 & & & \\
\hline & TWC3 & 0.707 & & & \\
\hline & TWC5 & 0.789 & & & \\
\hline & TWC6 & 0.780 & & & \\
\hline & TWC7 & 0.843 & & & \\
\hline & TWC8 & 0.862 & & & \\
\hline
\end{tabular}


Table 3: Results of the Discriminant Validity (HTMT)

\begin{tabular}{lccccccc}
\hline Variables & CR & EOR & IR & NM & PM & PR & SC \\
\hline CR & & & & & & & \\
EOR & 0.561 & & & & & & \\
IR & 0.621 & 0.332 & & & & & \\
NM & 0.131 & 0.351 & 0.059 & & & & \\
PM & 0.565 & 0.669 & 0.369 & 0.302 & & & \\
PR & 0.420 & 0.418 & 0.404 & 0.283 & 0.449 & & \\
TWC & 0.496 & 0.732 & 0.323 & 0.219 & 0.585 & 0.388 & \\
\hline
\end{tabular}

Note: $\mathrm{EOR}=$ Employee-Organization Relationship, $\mathrm{PR}=$ Problem Recognition, $\mathrm{CR}=$ Constraint Recognition, IR = Involvement Recognition, $\mathrm{NM}=$ Negative Megaphoning, $\mathrm{PM}=$ Positive Megaphoning, TWC $=$ Symmetrical Two-way Communication.

A path analysis was carried out to test the hypothesis. The analysis was performed with a bootstrapping procedure (bootstraps into 5000 samples) to obtain a statistical t-value and p-value from the path coefficient as presented in Table 4 and Figure 2.

Table 4: Hypothesis Testing Results

\begin{tabular}{lcccccc}
\hline \multicolumn{1}{c}{ Hypothesis } & $\boldsymbol{\beta}$ & $\mathbf{S E}$ & $\mathbf{t}$-value & $\mathbf{p}$-value & $\mathbf{f}^{2}$ & Remark \\
\hline H1a: EOR $\rightarrow$ PM & 0.376 & 0.065 & 5.764 & 0.000 & 0.114 & Supported \\
H1b: EOR $\rightarrow$ NM & -0.276 & 0.070 & 3.932 & 0.000 & 0.040 & Supported \\
H2a: EOR $\rightarrow$ PR & 0.403 & 0.045 & 8.939 & 0.000 & 0.194 & Supported \\
H2b: EOR $\rightarrow$ IR & 0.316 & 0.061 & 5.202 & 0.000 & 0.111 & Supported \\
H2c: EOR $\rightarrow$ CR & 0.526 & 0.047 & 11.276 & 0.000 & 0.382 & Supported \\
H3a: PR $\rightarrow$ PM & 0.137 & 0.049 & 2.778 & 0.005 & 0.025 & Supported \\
H3b: PR $\rightarrow$ NM & -0.214 & 0.051 & 4.166 & 0.000 & 0.039 & Supported \\
H4a: IR $\rightarrow$ PM & 0.034 & 0.051 & 0.661 & 0.508 & 0.001 & Not Supported \\
H4b: IR $\rightarrow$ NM & 0.088 & 0.056 & 1.570 & 0.117 & 0.006 & Not Supported \\
H5a: CR $\rightarrow$ PM & 0.193 & 0.054 & 3.559 & 0.000 & 0.036 & Not Supported \\
H5b: CR $\rightarrow$ NM & 0.053 & 0.057 & 0.935 & 0.350 & 0.002 & Not Supported \\
H6a: TWC $\rightarrow$ PM & 0.133 & 0.066 & 2.021 & 0.043 & 0.017 & Supported \\
H6b: TWC $\rightarrow$ NM & 0.040 & 0.068 & 0.593 & 0.553 & 0.001 & Not Supported \\
\hline Control Variables: & & & & & & \\
AG $\rightarrow$ PM & -0.194 & 0.076 & 2.562 & 0.010 & 0.015 & \\
AG $\rightarrow$ NM & 0.021 & 0.087 & 0.243 & 0.808 & 0.000 & \\
GE $\rightarrow$ PM & 0.018 & 0.038 & 0.477 & 0.633 & 0.001 & \\
GE $\rightarrow$ NM & -0.098 & 0.034 & 2.884 & 0.004 & 0.011 & \\
TN $\rightarrow$ PM & 0.162 & 0.078 & 2.076 & 0.038 & 0.011 & \\
TN $\rightarrow$ NM & -0.195 & 0.092 & 2.116 & 0.034 & 0.010 & \\
POS $\rightarrow$ PM & -0.036 & 0.046 & 0.790 & 0.430 & 0.002 & \\
POS $\rightarrow$ NM & -0.040 & 0.045 & 0.902 & 0.367 & 0.001 & \\
\hline
\end{tabular}

Note: $\mathrm{EOR}=$ Employee-Organization Relationship, $\mathrm{PR}=$ Problem Recognition, $\mathrm{CR}=$ Constraint Recognition, $\mathrm{IR}=$ Involvement Recognition, $\mathrm{NM}=$ Negative Megaphoning, $\mathrm{PM}=$ Positive Megaphoning, $\mathrm{TWC}=$ Symmetrical Two-way Communication, $\mathrm{AG}=$ Age, $\mathrm{GE}=$ Gender, $\mathrm{TN}=$ Tenure, POS $=$ Position .

EOR quality, problem recognition, involvement recognition, constraint recognition, and symmetrical communication can explain the positive megaphoning variable by $46.3 \%$, while the negative megaphoning variable is $14.9 \%$. Among the three variables, EOR has the most significant effect on megaphoning behavior, both positive and negative. 
Figure 2. Structural Model Test Results

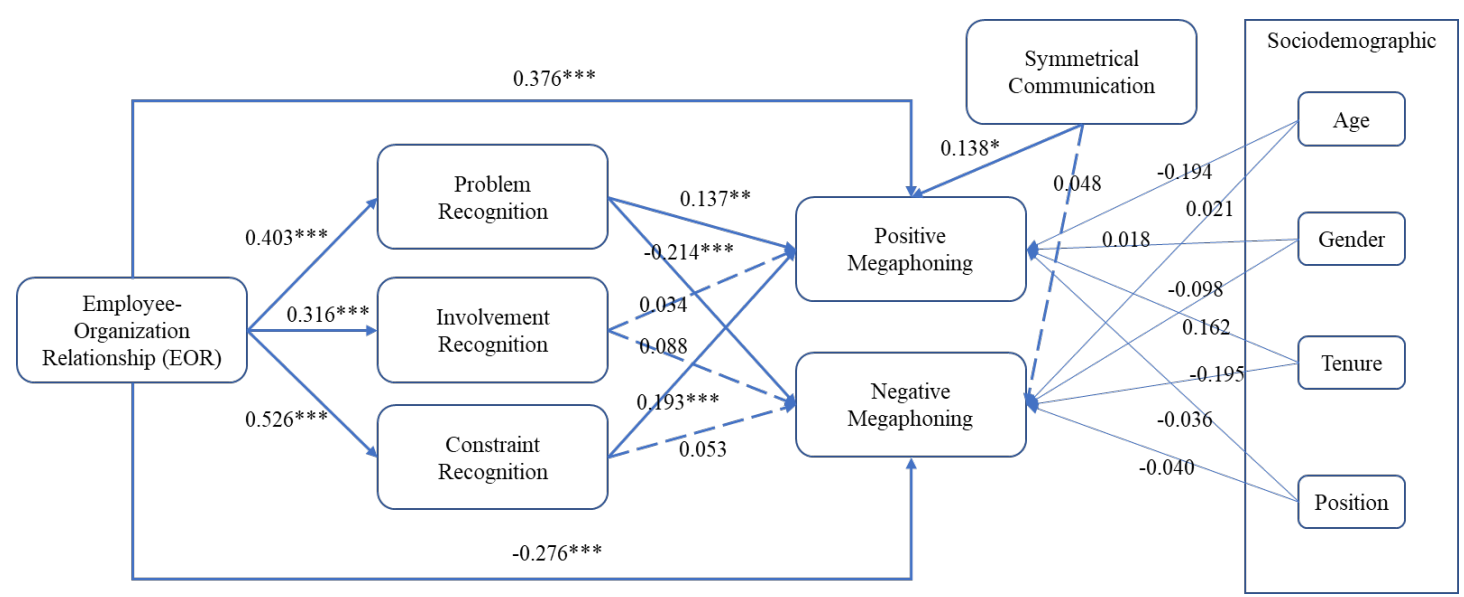

Note: $* \mathrm{p}<0.05 . * *<0.01 . * * * \mathrm{p}<0.001$. The dotted line shows an insignificant relationship.

H1 examined the effect of EOR quality on the positive and negative megaphoning behavior of employees regarding the crisis due to the COVID-19 pandemic. It was found that EOR had a significant positive effect on positive megaphoning $(\beta=0.376, \mathrm{t}$ $=5.764, \mathrm{p}=0.000)$ and a significant negative effect on negative megaphoning $(\beta=$ $-0.276, t=3.932, p=0.000$ ), which indicate that both $\mathrm{H} 1 \mathrm{a}$ and $\mathrm{H} 1 \mathrm{~b}$ were supported. In the context of the crisis due to the COVID-19 pandemic, good relations between employees and organizations during a crisis can encourage employees to advocate for the company and reduce employee intention to share negative communications externally.

In examining $\mathrm{H} 2$, this research tested the effect of EOR quality on employee-specific crisis perceptions. The result shows that EOR had a significant positive effect on the three specific crisis perceptions, namely problem recognition $(\beta=0.403, \mathrm{t}=8.939, \mathrm{p}=$ $0.000)$, constraint recognition $(\beta=0.526, \mathrm{t}=11.276, \mathrm{p}=0.000)$ and involve recognition $(\beta=0.316, t=5.202, p=0.000)$. Thus, all $\mathrm{H} 2$ were supported. In the context of the crisis caused by the COVID-19 pandemic, employees who have a good quality relationship with their organizations tend to recognize crises in the organization as serious problems and feel more involved in these problems and feel less constrained in resolving these problems in the workplace. The EOR variable can explain problem recognition, constraint recognition, and involvement recognition, respectively, for $16.2 \%, 27.6 \%$, and $10 \%$.

$\mathrm{H} 3$ tested the effect of problem recognition on megaphoning behavior during a period of crisis due to the COVID-19 pandemic. The finding shows that problem recognition had a significant effect on positive megaphoning $(\beta=0.137, t=2.778, p=0.005)$ and negative megaphoning $(\beta=-0.214, \mathrm{t}=4.116, \mathrm{p}=0.000)$, which supported H3a and $\mathrm{H} 3 \mathrm{~b}$. Regarding involvement recognition, the finding shows that involvement recognition insignificantly influenced positive megaphoning $(\beta=0.034, \mathrm{t}=0.661, \mathrm{p}=$ $0.508)$ and negative megaphoning $(\beta=0.088, \mathrm{t}=1.570, \mathrm{p}=0.117)$. Thus, both $\mathrm{H} 4 \mathrm{a}$ and $\mathrm{H} 4 \mathrm{~b}$ were not supported. Our findings also do not support H5a and H5b. Contrary to our hypothesis, the finding shows a significant positive effect of constraint recognition on positive megaphoning $(\beta=0.193, t=3.559, p=0.000)$. In contrast, the effect of constraint recognition on negative megaphoning is insignificant $(\beta=0.053, t=0.935$, 
$\mathrm{p}=0.350)$. These results indicate that in the context of the COVID-19 pandemic crisis, the tendency of employees to perform megaphoning behavior is triggered by their ability to recognize the crisis and perception over the constraint to overcome the crisis. This megaphoning behavior is presented in terms of positive megaphoning rather than negative one.

Lastly, the tests of symmetrical communication on megaphoning behavior show that symmetrical communication has a significant positive effect on positive megaphoning behavior $(\beta=0.133, \mathrm{t}=2.021, \mathrm{p}=0.043)$, but an insignificant effect on negative megaphoning behavior $(\beta=0.040, \mathrm{t}=0.593, \mathrm{p}=0.553)$. Thus, $\mathrm{H} 6$ is partially supported. The results indicate, in the context of the COVID-19 pandemic crisis, symmetrical communication between employees and their companies tends to encourage employees to spread positive information externally but does not affect their interest to spread negative information.

As presented in Table 4, some sociodemographic variables have significant statistical effects on megaphoning behavior. For instance, the influences of age and tenure on positive megaphoning behavior are statistically significant, while gender and tenure significantly influence negative megaphoning behavior. However, the analysis using PLS-SEM cannot be solely based on the $p$-value. A closer look at the effect size $\left(\mathrm{f}^{2}\right)$ is needed to assess whether the effect is substantially significant. This study finds that none of the effect of sociodemographic attributes on megaphoning behavior is substantially significant.

\section{Discussion}

This study contributes to the knowledge of internal crisis communication strategies by examining the relationship between the situational aspects that affect the motivation of employee communication behavior in times of crisis. In addition, this study also explains the effect of the type of crisis caused by external factors, namely the COVID19 pandemic.

This study finds that employees who have a good relationship with their company tend to share positive information about their company and do not spread negative information about their company externally during times of a crisis. This finding supports the results of previous studies by Kim and Rhee (2011), Lee (2017), and Mazzei et al. (2012), where the EOR encourages employees to support their organization during crisis periods and reduces the behavior of spreading negative employee information externally. If employees trust each other, have control mutuality, are satisfied with the organization, and are committed to the organization, they are more likely to show high performance, have high motivation to achieve the organization's goals, and protect the organization's reputation (Men, 2012, Morrison \& Robinson, 1997). As such, these tendencies lead them to say positive things about the organization during a crisis. In addition, a good EOR can have a positive strategic influence on the organization either in a normal or turbulent business environment (Kim \& Rhee, 2011).

The effect of EOR on megaphoning behavior is also mediated by their perception of a specific crisis. Employees who have good relations with their company tend to recognize crises as a critical problem, are urged to be more involved, and feel less 
constrained in solving the problem. This finding is in line with the results of research conducted by Hung (2005), Ki and Hon (2007), as well as Lee (2020). The mutual trust among employees and their mutual satisfaction with the company fosters their affective perceptions, thus affecting employees concerns for issues/problems, desires, and comfort in taking actions to solve problems and consider the problems facing the company as their own problems. Employee's perceptions about the issue/crisis ultimately affect the level of employee's motivation to be actively involved in positive and negative communication behavior towards an issue/crisis.

Furthermore, this study shows that only several dimensions of employee-specific crisis perceptions affect megaphoning behavior. This result contradicts Kim and Grunig (2011), who showed that when people were able to recognize the problem, be involved in the problem, and be less constrained in solving the problem, they tended to communicate more intensely in sharing and forwarding information. These results are also different from Lee's research (2019) that reported an insignificant relationship to the effect of problem recognition on positive megaphoning and negative megaphoning and the effect of involvement recognition on positive megaphoning. However, our findings partially support Lee's research (2020), where problem recognition and constraint recognition have a significant effect on employee's voicing in a crisis, but the effect of constraint recognition on positive megaphoning was positive.

In this study, megaphoning behavior is influenced by an employee's ability to recognize the crisis. When they recognize the COVID-19 pandemic as an organizational crisis, they tend to disseminate positive information rather than negative one to external parties. Interestingly, when employees feel more constrained to solve the crisis, they are more likely to spread positive information about the organization. This condition can happen due to the differences of crisis types being studied, where the crisis studied by Kim and Grunig (2011) is individual problems/issues in the U.S. at that time, such as the Iraq war, weight loss, and the practice of selling human organs in developing countries, while the crisis context in Lee's study (2020) is gender discrimination. The crisis context in this study has a higher level of uncertainty and time pressure than previous studies. The COVID-19 pandemic had not been anticipated before and originates from an external source to the company. It is highly uncertain, difficult to handle, has a long-term impact, a massive level of spread, and very broad coverage. Hence, employees are triggered to support the organization by spreading positive information externally. As the COVID-19 pandemic brings negative consequences not only to the organization, but also to the national economy, and the employees only have limited control to minimize the spreading of the virus, they are more motivated to perform positive megaphoning behavior to protect their organization and jobs.

This study also found that symmetrical communication between employees and the company only affects positive megaphoning behavior, which is different from the study by Men (2014) which found that symmetrical communication does not directly affect employee communication behavior, in this case, employee advocacy. Symmetrical communication can increase trust, credibility, openness, good feedback, adequacy of information, and tolerance for disagreement (Grunig, 1992), so that it can stimulate the employee's cognition and positive emotions when the company is experiencing a crisis. The symmetrical communication has no effect on employee's negative megaphoning because the COVID-19 pandemic is caused by external factors of the company. Thus, employees are less likely to blame the company for the crisis they are experiencing- 
thereby reducing their interest in spreading negative information about the company externally.

\section{Limitations and Directions for Further Research}

This study has several limitations that are expected to be addressed in future research. Further research can develop research models by considering other variables not included in this research model, such as non-active internal public, active internal public, referent criterion, situational motivation in problem solving, and communicative action in problem solving. In addition, the sample in this study is employees who work in a large-scale state-owned company in Indonesia, which may not represent every organization. Therefore, this study's findings cannot be generalized to other populations, such as private sectors, SMEs, or organization in other countries. Similar research can be conducted on different samples, such as employees working in medium or small organizations in different crisis contexts.

\section{Implications for Asian Business}

The year of 2020 has been a crucial year for the global economy, where businesses and governments face tough challenges to overcome the COVID-19 pandemic appropriately, quickly and adaptively to recover the economy. United Nations Conference on Trade and Development (2020) expects gross domestic product (GDP) to fall by around 4.3 per cent in 2020 , with an expected global recovery of 4.1 per cent in 2021.

The crisis in the corporate sector requires an analysis of what is happening, future projections and collaboration of related parties. A crisis in the company can cause unrest for the company's internal public. At the same time, companies need to consolidate internal resources for business recovery. For this reason, an internal crisis communication strategy is needed to ensure that the company's main objectives and values are maintained. Given that employee interactions with the external public can affect public relations output as well as the company reputation and the quality of public-organizational relations, it is important to understand employee communication when the company is facing a crisis because employees communicate more intensely during the crisis.

In the context of the COVID-19 pandemic crisis, the result shows that developing and keeping a good relationship with employees can encourage employees to share positive information and reduce their intention to share negative communications externally. A good relationship between the company and employees will foster employee's sense of ownership toward the organization. A good EOR as indicated by a high level of trust, mutual understanding of each other's rights and obligations, and a high level of satisfaction and commitment, improve employee cognitive perceptions of certain issue faced by the organization. They believe that the crisis needs to be solved immediately, feel a sense of involvement in the crisis, and feel empowered to solve it.

Furthermore, employees who recognize the crisis as their own problem and feel able to solve problem tend to spread positive information. It is because the crisis is triggered 
by the external factor and affects the global economy and their well-being. This is in accordance with the situational theory of problem solving (STOPS) which explains that communication behavior is determined by their specific perceptions as an outcome of a problem-solving process. Thus, good perceptions about an issue lead them to say positive things about the organization during a crisis (Kim \& Rhee, 2011).

This study reports that symmetrical communication between employees and their companies tends to encourage employees to spread positive information about the company to the outsiders. Symmetrical communication may create mutual understanding between organization leaders and employees and foster participative culture in the organization. This type of communication enables employees to understand better about the situation faced by the organization that influences their voicing behavior (Kim, 2018; Lee, 2020). The inclination to protect the organization during the crisis might be stronger in Asia. It is because Asian people hold collectivism values that prioritizing the group's interests over themselves and fostering group harmony. When employees know the situation faced by the organization during the COVID-19 pandemic, they are more likely to defend the organization by spreading positive information about the company to external parties. Therefore, organizational leaders should maintain a good relationship with their subordinates and implement symmetrical communication to increase employee's sense of belonging and sense of crisis so that they are keen to perform positive megaphoning behavior.

\section{References}

Center, A., \& Jackson, P., (2003), Public relations practices: Managerial case studies and problems, New Jersey, Prentice-Hall.

Coombs, W.T., (2007), "Protecting organization reputations during a crisis: The development and application of situational crisis communication theory", Corporate Reputation Review, vol. 10, no. 3, pp. 163-176.

Coombs, W.T., (2015), Ongoing Crisis Communication: Planning, managing, and responding, (4th ed.), Thousand Oaks, CA.

Coombs, W.T., \& Holladay, S.J., (2006), "Unpacking the halo effect: Reputation and crisis management", Journal of Communication Management, vol. 10, no. 2, pp. 123137.

Frandsen, F., \& Johansen, W., (2011), "The study of internal crisis communication: Towards an integrative framework", Corporate Communications: An International Journal, vol. 16, no. 4, pp. 347-361.

Gefen, D., Straub, D.W., \& Boudreau, M., C. (2020). Structural Equation Modelling and Regression: Guidelines for Research Practice, Communications of the Association for Information Systems, vol. 4, no. 7, pp. 1-77.

Grunig, J.E., (1992), What is Excellence in Management, Excellence in Public Relations and Communication Management (pp. 219-250), Hillsdale, NJ.

Grunig, J.E., \& Repper, F.C., (1992), Strategic Management, Public, and Issues, Excellence in Public Relations and Communication Management (pp. 117-158). Hillsdale, NJ.

Hair, J.F., Jr., Sarstedt, M., Hopkins, L., Kuppelwieser, V.G., (2014), "Partial least squares structural equation modeling (PLS-SEM): an emerging tool in business research", European Business Review, vol. 26, no. 2, pp.106-121.

Hair, J.F., Ringle, C.M., \& Sarstedt, M., (2015), "PLS-SEM: Indeed a silver bullet", Journal of Marketing Theory and Practice, 19(2), 139-151.

Henseler, J., Ringle, C.M., \& Sarstedt, M., (2015), "A new criterion for assessing 
discriminant validity in variance-based structural equation modeling", Journal of the Academy of Marketing Science, 43(1), 115-135.

Holtzhausen, D.R., (2002), "The effects of workplace democracy on employee communication behavior: Implications for competitive advantage", Competitiveness Review: An International Business Journal, vol. 12, no. 2, pp. 30-48.

Hon, L.C., \& Grunig, J.E., (1999), Guidelines for Measuring Relationships in Public Relations. Gainesville, FL: Institute for Public Relations, Commission on P.R. Measurement and Evaluation.

Hung, C.F., (2005), "Exploring types of organization-public relationships and their implications for relationship management in public relations", Journal of Public Relations Research, vol. 17, no. 4, pp. 393-426.

Johansen, W., Aggerholm, H.K., \& Frandsen, F., (2011), "Entering new territory: A study of internal crisis management and crisis communication in organizations", Public Relations Review, vol. 38, no. 2, pp. 270-279.

Kang, M., \& Sung, M., (2017), "How symmetrical employee communication leads to employee engagement and positive employee communication behaviors: The mediation of employee-organization relationships", Journal of Communication Management, vol. 21, no. 1, pp. 82-102.

Ki, E.J., \& Hon, L.C., (2007), "Testing the linkages among the organization-public relationship and attitude and behavioral intentions", Journal of Public Relations Research, vol. 19, no. 1, pp. 1-23.

Kim, J.N., \& Grunig, J.E., (2011), "Problem solving and communicative action: A situational theory of problem solving", Journal of Communication, vol. 61, no. 1, pp. $120-149$.

Kim, J.N., \& Rhee, Y., (2011), "Strategic thinking about employee communication behavior (ECB) in public relations: Testing the models of megaphoning and scouting effects in Korea", Journal of Public Relations Research, vol. 23, no. 3, pp. 243-268.

Kim, Y., (2018), "Enhancing employee communication behaviors for sensemaking and sense giving in crisis situations: Strategic management approach for effective internal crisis communication", Journal of Communication Management, vol. 22, no. 4, pp. 451-475.

Lee, Y., (2017), "Exploring the impacts of relationship on employee's communicative behaviors during issue periods based on employee position", Corporate Communications: An International Journal, vol. 22, no. 4, pp. 542-555.

Lee, Y., (2019), "Crisis perceptions, relationship, and communicative behaviors of employees: Internal public segmentation approach", Public Relations Review, vol. 45, no. 4, 2019, 101832 .

Lee, Y., (2020), "A situational perspective on employee communicative behaviors in a crisis: The role of relationship and symmetrical communication", International Journal of Strategic Communication, vol. 14, no. 2, pp. 89-104.

Mazzei, A., \& Ravazzani, S., (2015), "Internal crisis communication strategies to protect trust relationships: Study of Italian companies". International Journal of Business Communication, vol. 52, no. 3, pp. 319-337.

Mazzei, A., Kim, J.N., \& Dell’Oro, C., (2012), "Strategic value of employee relationships and communicative actions: overcoming corporate crisis with quality internal crisis communication", International Journal of Strategic Communication, vol. 6, no. 1, pp. 31-44.

Men, L.R., \& Bowen, S.A., (2017), Excellence in Internal Communication Management, New York, NY.

Men, L.R., (2011), "How employee empowerment influences organization-employee relationship in China", Public Relations Review, vol. 37, no. 4, pp. 435-437.

Men, L.R., (2014), "Why leadership matters to internal communication: Linking transformational leadership, symmetrical communication, and employee outcomes", Journal of Public Relations Research, vol. 26, no. 3, pp. 256-279.

Ministry of Finance of Republic of Indonesia, (2020, September 25), Ancaman resesi tak 
dapat dihindari, 92\% negara di dunia mengalaminya. Retrieved from https://www.kemenkeu.go.id/publikasi/berita/ancaman-resesi-tak-dapat-dihindari92-negara-di-dunia-mengalaminya.

Morrison, E.W., Robinson, S. L., (1997), "When employees feel betrayed: A model of how psychological contract violation develops", Academy of Management Review, vol. 22, no. 1, pp. 226-256.

Ni, L., Xiao, Z., Liu, W., \& Wang, Q., (2019), "Relationship management as antecedents to public communication behaviors: Examining empowerment and public health among Asian Americans", Public Relations Review, vol. 45, no. 5, 2019, 101835.

Park, S.H., Kim, J.N., \& Krishna, A., (2014), "Bottom-up building of an innovative organization: Motivating employee intrapreneurship and scouting and their strategic value", Management Communication Quarterly, vol. 28, no. 4, pp. 531560.

Ramanadhan, S., \& Viswanath, K., (2006), "Health and the information nonseeker: A profile", Health Communication, vol. 20, pp. 131-139.

Ramayah, T., Cheah, J., Chuah, F., Ting, H., \& Memon, M.A, (2018), Partial least squares structural equation modeling (PLS-SEM) using SmartPLS 3.0, 2nd ed. Kuala Lumpur: Pearson.

Strandberg, J.M., \& Vigsø, O., (2016), "Internal crisis communication: An employee perspective on narrative, culture, and sensemaking", Corporate Communications: An International Journal, vol. 21, no. 1, pp. 89-102.

Ulmer, R.R., Sellnow, T.L. \& Seeger, M.W., (2015), Effective Crisis Communication: Moving from Crisis to Opportunity (3rd ed.). Thousand Oaks, CA.

United Nation Conference on Trade and Development, (2020), Impact of The COVID-10 on Trade and Development: Transitioning to A New Normal, New York.

World Bank, (2020), East Asia and Pacific in the time of COVID-19: East Asia and Pacific economic update (April), Washington, DC: World Bank.

\section{Appendix}

\begin{tabular}{|c|c|c|}
\hline Variable & & Measurement Item \\
\hline \multicolumn{3}{|c|}{ Symmetrical Communication } \\
\hline & TWC1 & $\begin{array}{l}\text { I am comfortable talking to my manager about my } \\
\text { performance }\end{array}$ \\
\hline & TWC2 & $\begin{array}{l}\text { Most communication between management and other } \\
\text { employees in our company can be said to be two-way } \\
\text { communication }\end{array}$ \\
\hline & TWC3 & Our company encourages differences of opinion \\
\hline & TWC5 & $\begin{array}{l}\text { Employees are not afraid to speak up during meetings with } \\
\text { supervisors and managers }\end{array}$ \\
\hline & TWC6 & $\begin{array}{l}\text { The purpose of communication in our company is to help } \\
\text { managers be responsive to the problems of employees }\end{array}$ \\
\hline & TWC7 & $\begin{array}{l}\text { Supervisors encourage employees to express differences of } \\
\text { opinion }\end{array}$ \\
\hline & TWC8 & $\begin{array}{l}\text { I am comfortable talking to my manager when things are } \\
\text { going wrong }\end{array}$ \\
\hline \multicolumn{3}{|c|}{ Employee-Organization Relationship } \\
\hline \multirow[t]{2}{*}{ Trust } & TR1 & $\begin{array}{l}\text { Whenever this company makes an important decision, I know } \\
\text { it will be concerned about me }\end{array}$ \\
\hline & TR2 & The company can be relied on keeping its promises \\
\hline
\end{tabular}


Control Mutuality

Commitment

Problem Recognition

Constraint Recognition

Involvement Recognition

Satisfaction

Involvement Recognition

Positive Megaphoning
TR3 I believe that this company takes my opinions into account when making decisions

TR4 . My organization has the ability to accomplish what it says it will do

TR6 : I feel very confident about this company's skills

CMU3 : This company really listens to what I have to say

CMU4 : The management of my organization gives people like me enough say in the decision-making process

CMU5 . The organization and I agree on what we can expect from one another

CMU6 : The organization and I are cooperative with each other

CMT1 . I feel that this company is trying to maintain a long-term commitment to me

CMT2 . I can see that this company wants to maintain a relationship with me

CMT3 . Compared to other organizations, I value my relationship with this organization more

ST1 : Overall, I am happy with this company

ST2 : Both my organization and I benefit from the relationship

ST3 : I am happy in my interactions with this company

ST4 : Generally speaking, I am pleased with the relationship my organization has established with me

\section{Situational Theory of Problem Solving (STOPS)}

PR1 : I think this is a serious social or national problem/issue

PR2 : I am very concerned about this problem/issue

PR4 : Something needs to be done to improve this problem/issue

PR5 : I believe people need to pay more attention to this problem/issue

PR6 . The parties involved should take action to solve this problem/issue

PR7 : I take this problem/issue seriously

CR1 : I can improve the situation by taking action

CR3 : I can make a difference in the way this problem is solved

CR4 : Ifeel I can improve the problematic situation

CR5 . Ifeel like my ideas matter to those in the government (or corporation) who are working on this problem/issue

CR7 : Ifeel comfortable taking action regarding this problem/issue

IR1 : I recognize a strong connection between myself and this problem IR2 : I see a close connection between myself and this

IR3 : Ifeel a strong relationship between myself, this problem/issue, and someone close to me

IR4 : I am connected with this problem/issue and its consequences

IR5 : This problem/issue has serious consequences for me and for someone I care about

\section{External Communication Behavior}

PM1 : $\begin{aligned} & \text { Write positive comments or advocating posting for my } \\ & \text { organization on the Internet }\end{aligned}$ 


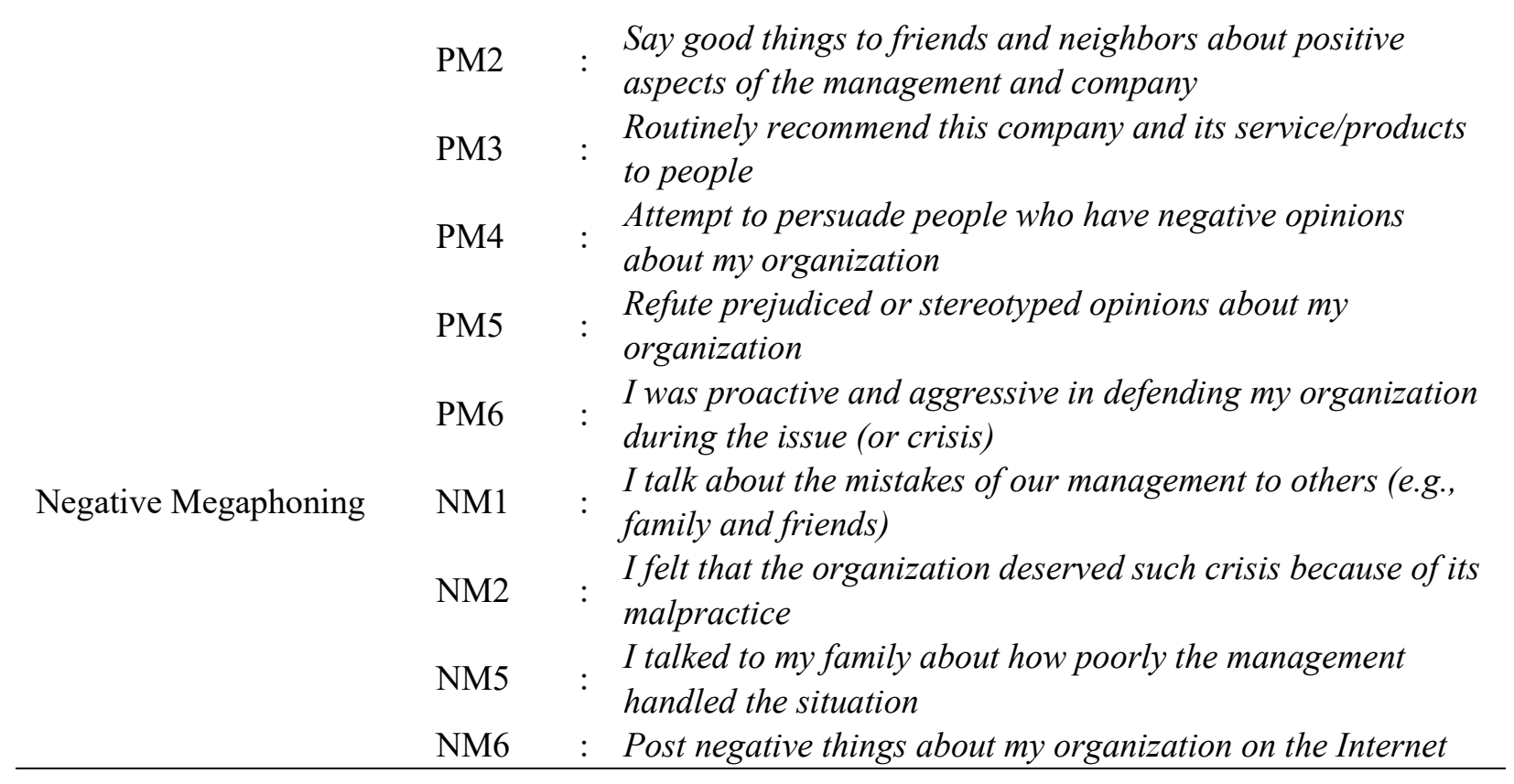

